\title{
Pengaruh komposisi perekat dan diameter briket biopellet terhadap karakteristik dan temperatur pembakaran pada kompor gasifikasi
}

\author{
Tri Cahyo Wahyudi ${ }^{*}$, Sulis Dri Handono 2 , Lukito Dwi Yuono ${ }^{3}$, Rohyani ${ }^{4}$ \\ 1,2,3 Jurusan Teknik Mesin, Fakultas Teknik, Universitas Muhammadiyah Metro \\ Jl. Ki Hajar Dewantara 15 A Kota Metro, Lampung, Indonesia \\ ${ }^{4}$ Prodi Teknik Mesin, Fakultas Teknik, Universitas Muhammadiyah Metro \\ Jl. Ki Hajar Dewantara 15 A Kota Metro, Lampung, Indonesia \\ ${ }^{*}$ Corresponding author: tricahyowahyudi3@gmail.com
}

\begin{abstract}
Biopellet is a type of solid fuel based on biomass waste which has a smaller size than briquettes. The purpose of this study was to determine the effect of adhesive composition and the effect of the diameter of biopellet briquettes on the characteristics and temperature and combustion time of the gasification stove. The method used was a mixture of $40 \%$ sawdust biomass and 60\% coconut shell charcoal by varying the adhesive as much as 20\%, 25\%, 30\% on $4 \mathrm{~mm}$ and $7 \mathrm{~mm}$ diameter biopellet briquettes. Based on the test results, it is known that the adhesive composition affects the temperature and time produced during combustion. The highest temperature reached $713.2^{\circ} \mathrm{C}$ with an adhesive percentage of $20 \%$ at a diameter of 7 $\mathrm{mm}$ biopellet briquettes with a flash time of 26 minutes. While the lowest temperature reached $653.00 \mathrm{C}$ with $30 \%$ adhesive percentage on $4 \mathrm{~mm}$ diameter biopllet briquettes and 30 minutes of flame time. For the characteristics of biopellet briquettes from laboratory tests, the highest moisture content value was $8.10 \%$ in $30 \%$ adhesive at $4 \mathrm{~mm}$ diameter for the highest ash content value $9.45 \%$ at $30 \%$ adhesive variation at $4 \mathrm{~mm}$ diameter and the highest calorific value reached $4571.64 \mathrm{cal} / \mathrm{g}$ of $20 \%$ adhesive vari at $7 \mathrm{~mm}$ diameter.
\end{abstract}

Keywords: Biopllet, briquettes, biomass, gasification stove.

\begin{abstract}
Abstrak
Biopellet merupakan jenis bahan bakar padat berbasis limbah biomassa yang memiliki ukuran yang lebih kecil dari briket. Tujuan penelitian adalah untuk mengetahui pengaruh komposisi perekat dan pengaruh diameter briket biopellet terhadap karakteristik dan temperatur serta waktu pembakaran pada kompor gasifikasi. Metode yang digunakan campuran biomassa serbuk gergaji $40 \%$ dan arang tempurung kelapa $60 \%$ dengan menvariasikan perekat sebanyak $20 \%, 25 \%, 30 \%$ pada diameter briket biopellet $4 \mathrm{~mm}$ dan $7 \mathrm{~mm}$. Berdasarkan hasil pengujian diketahui bahwa komposisi perekat mempengaruhi termperatur serta waktu yang dihasilkan saat pembakaran. Temperatur tertinggi mencapai $713,2^{\circ} \mathrm{C}$ dengan persentase perekat $20 \%$ pada diameter briket biopellet $7 \mathrm{~mm}$ dengan waktu nyala 26 menit. Sedangkan temperatur terendah mencapai $653,0^{\circ} \mathrm{C}$ dengan persentase perekat $30 \%$ pada diameter briket biopllet $4 \mathrm{~mm}$ dan waktu nyala 30 menit. Untuk karakteristik briket biopellet dari uji laboratorium didapat nilai kadar air tertinggi 8,10\% pada perekat $30 \%$ pada diameter $4 \mathrm{~mm}$ untuk nilai kadar abu tertinggi $9,45 \%$ pada variasi perekat $30 \%$ pada diameter $4 \mathrm{~mm}$ dan nilai kalor tertinggi mencapai $4571,64 \mathrm{cal} / \mathrm{g}$ dari vari perekat $20 \%$ pada diameter $7 \mathrm{~mm}$.
\end{abstract}

Kata kunci: Briket, biopllet, biomassa, kompor gasifikasi.

\section{Pendahuluan}

Pada masa sekarang ini dengan seiring perkembangannya zaman dan pertumbuhan jumlah penduduk di Indonesia kebutuhan energi semakin meningkat, energi sangat diperlukan untuk kegiatan industri, jasa, perhubungan dan rumah 
tangga. Sampai saat ini, penggunaan energi masih menggunakan bahan bakar fosil seperti minyak bumi, batubara dan gas yang semakin hari harganya makin meningkat dan langka. Perlunya adanya energi alternatif sebagian pilihan utama untuk mengatasi krisisnya energi saat ini, salah satu energi alternatif yang bisa dimanfaatkan yaitu sebagai bahan bakar. Biomassa merupakan sumber energi yang bersih dan dapat diperbaharui yang di hasilkan melalui proses fotosintesis, baik itu berupa produk maupun berupa limbah. Biomassa merupakan energi terbarukan dalam bentuk energi padat yang diperoleh dari tumbuhan maupun limbah industri dan dikenal sebagai hijau baik yang langsung dipakai atau diproses terlebih dahulu [1].

\section{Tinjauan Pustaka}

Energi terbarukan merupakan energi alternatif yang bersifat pembaharuan secara terus menerus, energi terbarukan telah tersedia secara berlimpah di alam, keberadaan energi terbarukan telah berkesinambungan dengan masyarakat dan memiliki potensi yang cukup optimal sebagai pengganti energi fosil, namun secara garis besar energi terbarukan belum termanfaatkan sepenuhnya dikarenakan teknologi dan pengetahuan masyarakat yang menjadi terkendalanya dalam hal pemanfaatan energi terbarukan tersebut. Salah satu contoh adalah bentuk energi terbarukan adalah energi alternatif biomasa yang berupa serbuk gergaji, sekam padi dan yang lainya, energi tersebut biasanya berupa limbah buangan atau sisa hasil oprasi suatu kegiatan masyarakan yang hanya dibuang ataupun dibakar.

Energi biomassa potensial ini sejauh ini telah banyak dikembangkan dengan para penguji ataupun peneliti dengan tujuan untuk memanfaatkan energi potensial tersebut. Bentuk pemanfaatan yang berbeda salah satunya pemanfaatan energi biomassa adalah kompor gasifikasi yang merupakan projek pembaharuan dari kompor tungku tradisional, dan akan terus dikembangkan untuk mendapatkan kinerja kompor optimal untuk kompor gasifikasi tersebut.

\section{Biomassa}

Secara umum, biomassa adalah bahan yang dapat diperoleh secara langsung atau tidak langsung dari tanaman yang digunakan sebagai energi atau material dalam jumlah yang besar. Biomassa disebut sebut sebagai sumber daya yang diperoleh dari hayati [3]. Biomassa merupakan salah satu jenis bahan bakar padat selain dari batubara. Biomassa sendiri terdiri dari beberapa komponen yaitu kadar air, mudah menguap. Dalam proses pengeringan akan menghilangkan kelembaban, pemanasan yang merupakan tahapan pirolisis akan melepaskan volatile, pembakaran arang melepaskan karbon terikat dan sisa pembakaran dan menghasilkan abu [4].

Pada pemanfaatannya biomasa juga harus dipertimbangkan karena memiliki beberapa keunggulan maupun kekurangan yang harus dipahami keunggulan pada biomasa yaitu: meminimalisir limbah organik, mengurangi efek gas rumah kaca, menguangi polusi udara yang semakin meningkat, mengurangi ketergantungan terhadap bahan bakar fosil. Meskipun dengan adanya keuntungan, akan tetapi energi biomassa juga memiliki beberapa kelemahan seperti: sumber terbatas, mahal, dan menyebabkan polusi dengan keuntungan dan kelemahan diatas maka dapat dipertimbangkan dalam hal penggunaanya [5].

Keunggulan yang dimiliki oleh biomassa,

1. Memiliki potensi yang melimpah ruah dilingkungan sekitar.

2. Sumber energi yang dapat diperbaharui.

3. Mudah didapatkan.

Pemanfaatan biomassa sebagai bahan bakar alternatif terbarukan merupakan solusi yang tepat untuk mengatasi permasalahan yang muncul akibat penggunaan bahan bakar fosil. Pada pemanfaatan energi biomassa memiliki banyak keuntungan dari sisi lingkungan 
yaitu untuk mengurangi efek gas rumah kaca, mengurangi bau yang tidak sedap, mencegah penyebaran penyakit.

Pemanfaatan limbah seperti ini secara ekonomi dan sangat kompotitif seiring naiknya harga bahan bakar minyak. Disamping itu juga, prinsip dari tanpa limbah merupakan praktek pertanian yang ramah lingkungan dan berkelanjutan. Dengan banyaknya potensi biomassa yang belum dimaksimalkan hal ini proses pemanfaatannya disini dalam penelitian ini, peneliti akan menggunakan biomassa campuran yang berupa arang dari tempurung kelapa yang akan dipadukan dengan serbuk gergaji dan sekam padi serta lem (kayu) putih fox sebagai campuran perekat yang dimana akan dijadikan bentuk serta ukuran pellet untuk mempermudah proses pembakaran.

\section{Jenis-jenis biomassa}

Biomassa merupakan jenis sumber energi yang dihasilakan oleh sisaan tumbuhan dan limbah organik lainnya, selain itu biomassa bisa dimanfaatkan untuk bahan bakar kompor gasifikasi dan dapat mengurangi penggunaan bhan bakar fosil terus menerus. Adapun beberapa jenis biomassa yang bisa digunakan sebagai bahan bakar alternatif:

\section{1). Serbuk Gergaji}

Serbuk gergaji berasal dari bekas sisa potongan kayu akibat gesekan dari gergaji sehingga menimbulkan serpihan ataupun serbuk yang menjadi limbah dan tidak digunakan kembali, sama halnya dengan halnya dengan sekam padi, pemanfaatan limbah ini bisa menggunakan salah satunya kompor gasifikasi yang dimana karena bentuk dan ukuran serbuk gergaji akan dengan mudah untuk terbakar dan tujuan lainya tentunya untuk menggurangi limbah biomasa serbuk gergaji yang ada. Serbuk gergaji biasanya hanya dimanfaatkan sebagai media tanam karena mampu dengan baik menjadi media penyerap air serta unsur hara pada tanaman.

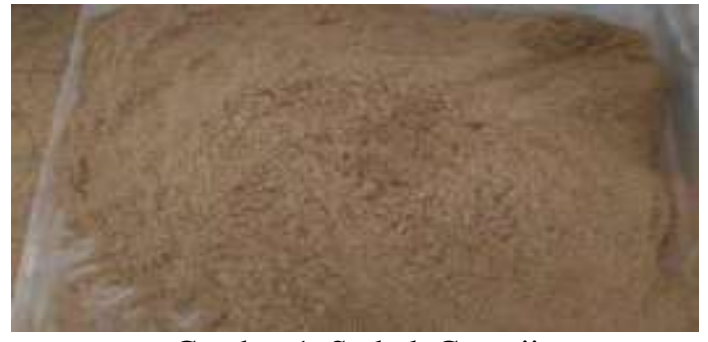

Gambar 1. Serbuk Gergaji

2). Arang

Arang merupakan suatu padatan yang berpori yang mengandung $85-95 \%$ karbon, yang dihasilkan dari bahan-bahan yang mengandung karbon dengan pemanasan pada suhu tinggi. Dalam pemanasan berlangsung, diusahakan agar tidak terjadi kebocoran udar didalam ruangan pemanasan sehingga bahan yang mengandung karbon tersebut hanya terkarbonisasi dan tidak teroksidasi. Arang selain digunakan untuk bahan bakar, arang juga dapat digunakan sebagai adsorben (penyerap). Arang memiliki daya serap yang ditentukan oleh luasan partikel daya serat ini lebih kuat dan lebih tinggi apabila dilakukan aktivasi dengan aktif faktor bahan-bahan kimia ataupun dengan pemanasan temperatur tinggi dan itu disebut dengan arang aktif.

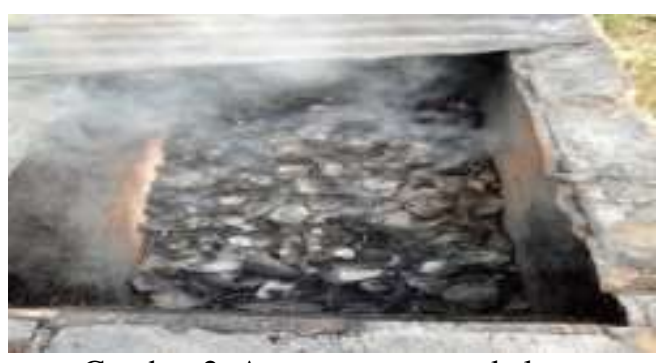

Gambar 2. Arang tempurung kelapa

Arang aktif dapat menyerap gas ataupun senyawa-senyawa kimia dan sifat serap yang selektif, mengacu pada besar ataupun volume pori-pori dan luas permukaan daya serapnya yaitu $25-1000 \%$ terhadap arang aktif. Jenis arang ini memiliki dua tipe yaitu sebagai pemucat dan penyerap uap.

\section{Perekat biopellet}

Perekat biopellet adalah untuk merekatkan partikel-partikel zat dalam bahan pada proses pembuatan briket biopellet maka diperlukan zat perekat 
sehingga dihasilkan briket biopellet yang kompak. Berdasarkan fungsi dari perekat dan kualitasnya, pemilihan bahan perekat dapat dibagi antara lain mudah terbakar dan tidak berasap, tidak mengeluarkan bau, tidak beracun dan tidak berbahaya serta mudah didapat dalam jumlah bnyak dan murah.

\section{Biopellet}

Bahan bakar biomassa yang pada umumnya digunakan secara langsung ialah sebetan dan serbuk gergajian. Serbuk gergajian diproses lanjutan berupa pengeringan dan pengepresan dan dijadikan bahan bakar yang disebut biopellet. Biopellet merupakan jenis bahan bakar padat berbasis limbah biomassa yang memiliki ukuran yang lebih kecil dari briket [6]. Keunggulan dari biopellet ini adalah dapat meningkatkan nilai kalor yang dihasilkan dari proses pembakaran. Selain itu ukuran dan keseragaman biopellet juga dapat memudahkan dalam proses pemindahan dari tempat satu ke tempat lainnya. Selain itu memiliki konsistensi dan efisiensi pembakaran yang dapat menghasilkan emisi yang lebih rendah dibandingkan dengan jenis lainnya [7]. Pellet ini dibuat dengan menghancurkan bahan baku dan dengan bantuan perekat biasanya tapioka, kemudian dilakukan pencetakan dengan alatnya yang bernama pellet mill. Bahan tambahan perekat tidak melebihi 5\% karena semakin besar penambahan perekat, makan menimbulkan bertambahnya kadar air pada biopellet tersebut.

\section{Diemeter briket biopellet}

Diameter biopellet merupakan ukuran yang ditentukan untuk membentuk briket biopellet, besar kecilnya diameter pada biopellet memiliki pengaruh terhadap pembakaran, semakin kecilnya ukuran diameter biopellet akan mempermudah pembakaran. Dengan memberikan bentuk serta ukuran diameter yang sama dan rata pada biopellet maka juga akan mempermudah bahan bakar untuk terbakar secara merata dengan begitu energi panas yang dihasilkan juga akan lebih maksimal.
Penggunaan komposisi perekat dan diameter briket biopelet diharapkan mampu meningkatkan nilai kalor dan karakteristik briket biopelet terhadap temperatur, serta waktu pembakaran pada kompor gasifikasi, dan memperoleh hasil yang baik [8].

\section{Kompor gasifikasi}

Kompor gasifikasi merupakan adalah alat yang terdiri dari tungku dan ruang bakar yang didesain untuk pembakaran tingkat gasifikasi yang mudah dilakukan dengan pasokan udara yang di tentukan untuk mendorong sin-gas untuk terbakar dan dengan tujuan kualitas bakar yang dihasilkan lebih baik dari kompor biomasa. Ada beberapa metode dalam gasifikasi yaitu: metode konsep atas, konsep bawah dan konsep silang, dan pada penelitian ini menggunakan kompor gasifikasi konsep menyala atas yang dimana memeliki keunggulan mekanismenya sederhana, dan memiliki efesiensi panas yang baik.

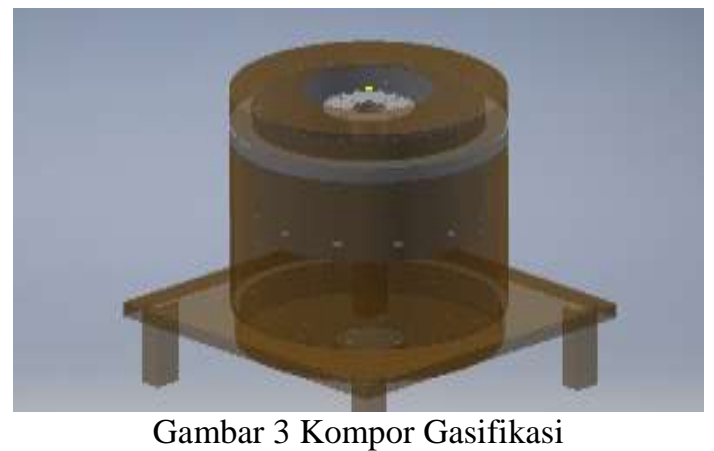

\section{Metode Penelitian}

Dalam penelitian ini peneliti melakukan pengujian pada bahan bakar untuk mendapatkan nilai dan data yang akurat. Pada proses pengujiannya peneliti menggunakan kompor gasifikasi dengan bahan bakar briket biopellet, berikut gambaran umum sistematika penelitian sebagai berikut: 


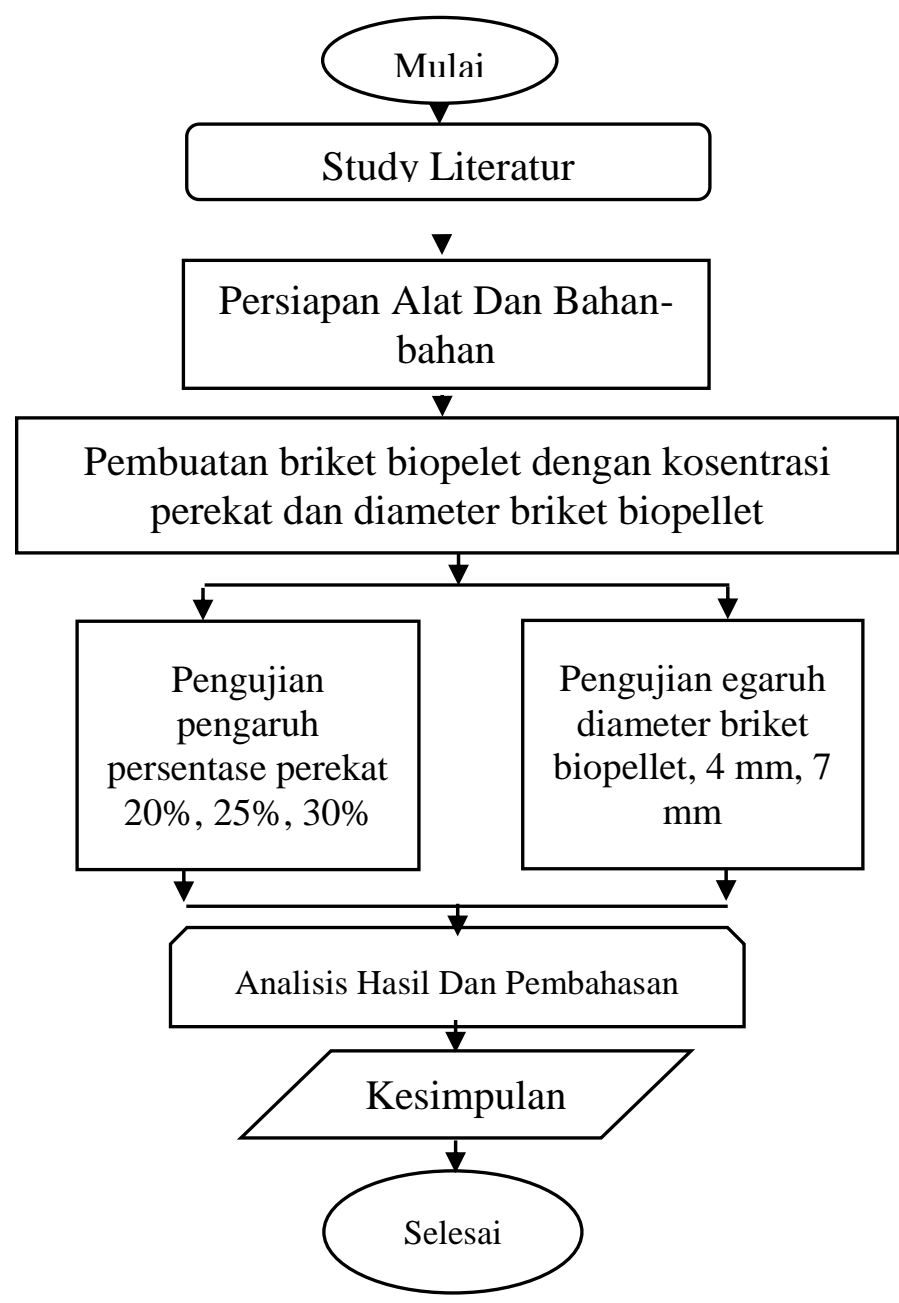

Gambar 1. Diagram alir penelitian

Prosedur yang digunakan pada penelitian ini adalah sebagai berikut:

a. Prosedur pada pembuatan kompor gasifikasi.

1) Mengkaji dan melakukan tahap perencanaan dari segi desain, bahan dan biaya yang dibutuhkan.

2) Setelah perencanaan dibuat matang, kemudian dilakukan proses pengerjaan atau pembuatan rangka gasifikasi.

3) Pada plat baja dibentuk menjadi silinder dan dipasang untuk bagian dinding luar dan bagian tabung bakar pada kompor gasifikasi.

4) Setelah rangka terbentuk dan dirangakai, lalu di pasangkan di komponen-koponen kompor gasifikasi seperti rotary fan, dan tabung beserta burner.
5) Kemudian dilakukan pengujian dan pengambilan data ketika semua komponen telah terpasang dan dapat digunakan sesuai dengan fungsinya dan ukuran.

b. Prosedur pada pembuatan variasi diameter pada plat lubang pembentukan briket biopellet.

1) Menentukan ukuran pada variasi diameter lubang yang akan dibentuk pada plat mesin alat pembuat pellet

2) Kemudian memotong plat melingkar sesuai dangan ukuran plat

3) Kemudian memasang platnya pada pembuat pellet tersebut.

4) Selanjutnya mesin alat pembuat pellet tersebut telah siap untuk membentuk arang biopellet campuran.

c. Prosedur penambahan perekat dengan persentase perekat sebesar $20 \%, 25 \%$, $30 \%$.

1) Menyiapkan alat dan bahan yang akan digunakan

2) Menakar biomassa sesuai dengan ukuran yang ditentukan yaitu per 1000 gram atau $1 \mathrm{~kg}$.

3) Mencacah dan menyaring biomassa yang digunakan dengan ukuran 5 mesh.

4) Kemudian dilakukan pengeringan secara alami oleh sinar matahari sebelum bahan dicampurkan untuk mengurangi kadar air.

5) Mencampur biomassa yang telah dikeringkan dengan arang dan variasi perekat sebanyak $20 \%, 25 \%$, $30 \%$.

6) Kemudian dilakukan percetakan menggunakan mesin penggiling daging yang plat pembentuk biopelletnya telah divariasikan yaitu, $4 \mathrm{~mm}, 7 \mathrm{~mm}$, menggunakan tekanan mekanisme manual yang diputar menggunakan tangan, dan dilakukan pemotongan menggunakan pisau agar hasilnya merata.

7) Setelah arang biopellet terbentuk kemudian dilakukan pengeringan kembali secara alami yaitu dengan 
memanfaatkan panas dari sinar matahari.

8) Tahapan akhir yaitu tahap analisa dan pengujian untuk mendapatkan kualitas yang baik dari arang biopellet.

\section{Hasil dan Pembahasan}

Adapun hasil pengujian dari penelitian yang didapatkan pada pengambilan data merupakan data yang aktual dari hasil pengujian yang dilakukan, dalam pengambilan data serta gambar.

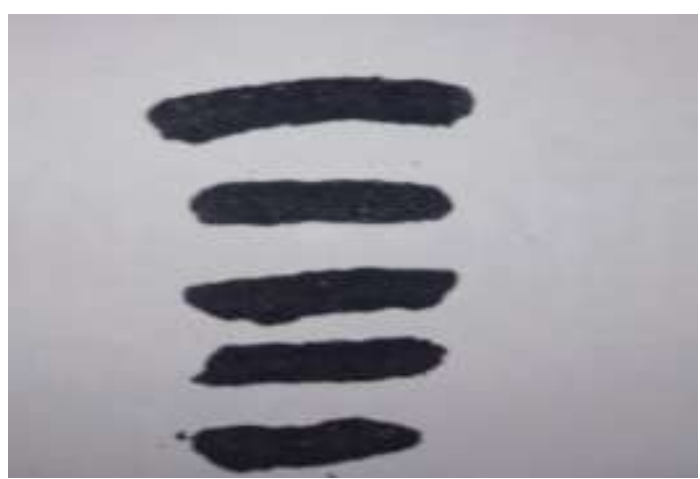

Gambar 4. hasil briket biopelet Serbuk Gergaji Pada Diameter $7 \mathrm{~mm}$ Dengan Persentase Perekat $20 \%$

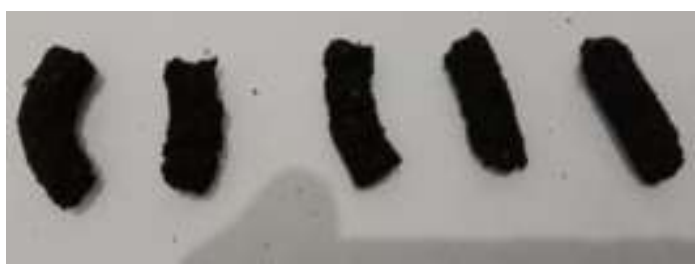

Gambar 5. hasil briket biopelet Sekam Padi Pada Diameter $7 \mathrm{~mm}$ Dengan Persentase Perekat $20 \%$

\section{Pengaruh Komposisi Perekat Terhadap Karakteristik Dan Temperatur Pembakaran Biopellet Pada Kompor Gasifikasi.}

Hasil data dari pengujian yang didapat dari penelitian ini bertujuan untuk diketahui briket biopellet terhadap karakteristik dan temperatur pembakaran.

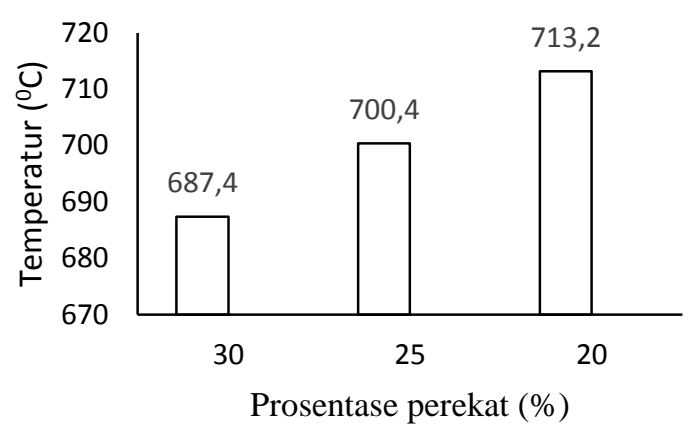

Gambar 6. Grafik temperatur pada variasi perekat briket biopellet.

Pada gambar 5. Grafik variasi perekat terhadap temperatur pembakaran didapatkan data bahwa variasi perekat sangat mempengaruhi besarnya temperatur yang didapatkan dimana dalam penelitian ini digunakan variasi perekat sebanyak 20 $\%$, $25 \%$, dan $30 \%$. Dan dapat diketahui semakin banyak komposisi dari perekat lem fox maka temperatur yang didapatkan juga semakin kecil. Hal ini disebabkan karena sifat lem fox yang berbahan dasar air memiliki kandungan air walaupun telah melalui proses pengeringan secara alami namun kandungan air pada lem fox masih tinggi jadi membuat nilai kalor juga semakin kecil dan temperatur yang dihasilkan dalam pembakaran juga semakin kecil.

\section{Pengaruh variasi diameter Terhadap Karakteristik Biopellet Serta Temperatur Pembakaran Briket Biopellet Pada Kompor Gasifikasi.}

Pengambilan data dilakukan pada saat pengujian untuk mengetahui pengaruh yang didapatkan dari variasi diameter biopellet yaitu $4 \mathrm{~mm}$ dan $7 \mathrm{~mm}$ terhadap temperatur serta waktu yang didapatkan pada saat pembakaran. 


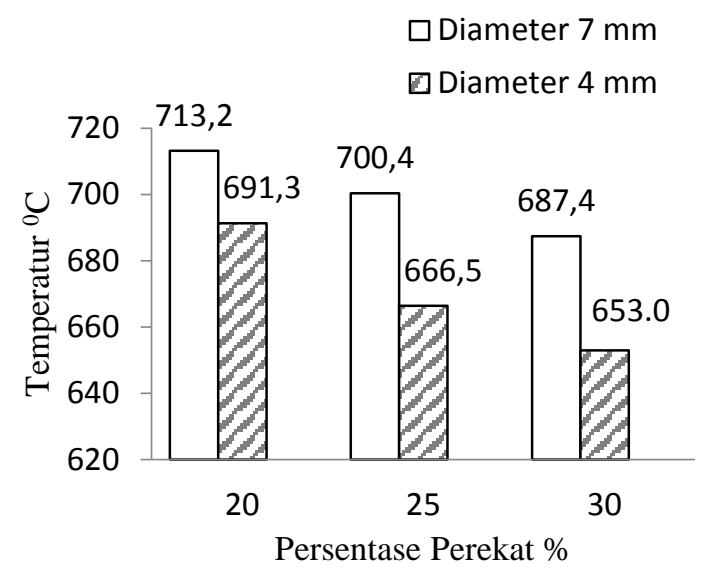

Gambar 7. Grafik pengaruh variasi diameter briket biopellet terhadap temperatur pembakaran.

Untuk pengaruh variasi diameter briket biopellet terhadap temperatur pembakaran briket biopellet didapatkan hasil pengujian dimana diameter briket biopellet sangat mempengaruhi temperatur pada pembakaran, dengan variasi diameter $7 \mathrm{~mm}$ dan $4 \mathrm{~mm}$ memiliki pengaruh yang sangat besar, pada diameter $7 \mathrm{~mm}$ untuk briket biopellet temperatur tertinggi mencapai $713,2^{\circ} \mathrm{C}$ dengan persentase perekat yang digunakan $20 \%$ dan untuk temperatur terendah mencapai $653,0^{\circ} \mathrm{C}$ terdapat pada diameter $4 \mathrm{~mm}$ pada persentase $30 \%$. Hal ini disebabkan karena diameter $4 \mathrm{~mm}$ mempunyai kerapatan yang lebih besar ketimbang pada diameter $7 \mathrm{~mm}$ sehingga pori-pori yang ada pada bahan lebih sedikit dan luas permukaan antar partikel lebih besar memungkinkan oksigen yang bertumbukan semakin banyak sehingga laju oksidasi semakin besar dan menghasilkan nilai pembakaran yang baik [9].

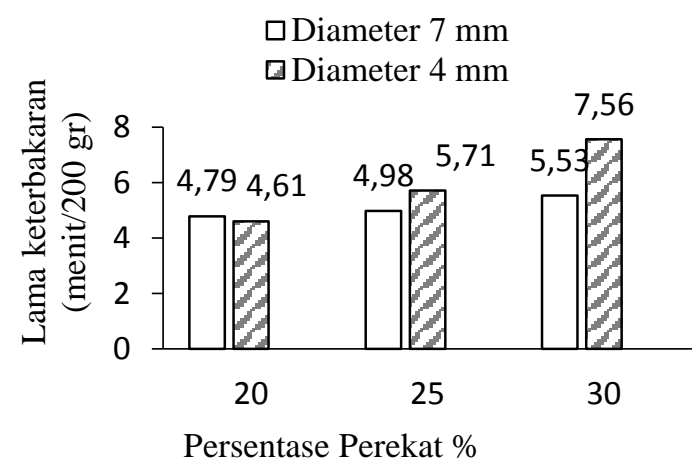

Gambar 8. Grafik pengaruh variasi diameter briket biopellet terhadap waktu Pembakaran.
Pada pengaruh variasi diameter briket biopellet terhadap waktu pembakaran gambar 7 sangat berpengaruh terhadap waktu keterbakaran dan diameter, dapat dilihat dari hasil pengujian pembakaran pada diameter briket biopellet $4 \mathrm{~mm}$ memiliki tingkat lama keterbakaran tertinggi mencapai 7,56 menit/200 gram dengan persentase perekat $30 \%$ dan untuk diameter $7 \mathrm{~mm}$ memilki lama keterbakaran terendah yaitu 4,79 menit/200 gram. Jadi dari hasil pengujian pembakaran pada diameter briket biopellet $4 \mathrm{~mm}$ dengan persentase perekat $30 \%$ memiliki hasil lebih baik dari standar karakteristik biopellet yang hanya mencapai nilai 5,42 menit/200 gram dilihat pada tabel 1. Karakteristik biopellet [10], dan untuk diameter briket biopellet 7 mm pada persentase perekat $20 \%$ memiliki waktu lama keterbakaran di bawah standar karakteristik biopellet yang hanya 4,79 menit/200 gram.

Pengujian lab dilakukan untuk mengetahui nilai kadar / tingkat kandungan air, kadar abu dan nilai kalor yang terkandung pada briket biopellet dan didaptkan hasil sebagai berikut:

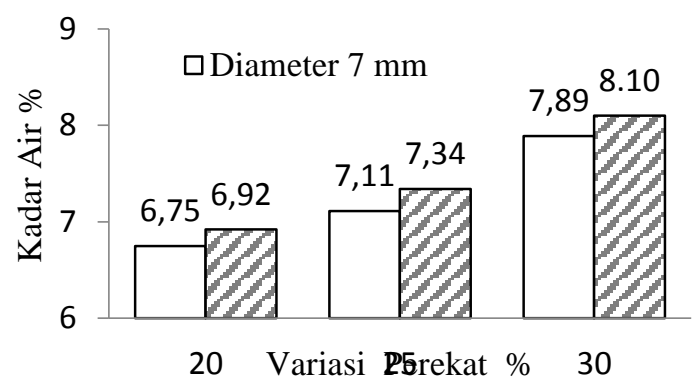

Gambar 9. Grafik perbandingan nilai kadar abu briket biopellet.

Pada gambar garafik 8 menunjukan bahwa semakin banyak komposisi perekat yang diberikan maka kadar airnya akan semakin tinggi, hal ini disebabkan karena jenis perekat yang digunakan, yang dimana perekat lem fox berbahan dasar air jadi memiliki nilai kandungan air tinggi sehingga hasil laboratorium dengan variasi perekat terbanyak akan lebih tinggi kandungan kadar airnya. Dan mendapat nilai kandungan kadar air briket biopellet tertinggi sebesar 8,10\% didapatkan dari variasi perekat $30 \%$ pada diameter briket 
biopellet $4 \mathrm{~mm}$, sedangkan kadar air terendah $6,75 \%$ pada persentase perekat $20 \%$ pada diameter $7 \mathrm{~mm}$. perlakuan pemberian perekat berpengaruh terhadap kadar air, penggunaan perekat lem fox lebih meninggkat kadar air biobriket, hal itu disebabkan karena biobriket dengan pemberian perekat lem fox lebih tinggi nilai karaptannya dan memiliki pori-pori yang kecil,sehinnga air sulit menguap saat proses pengovenan.

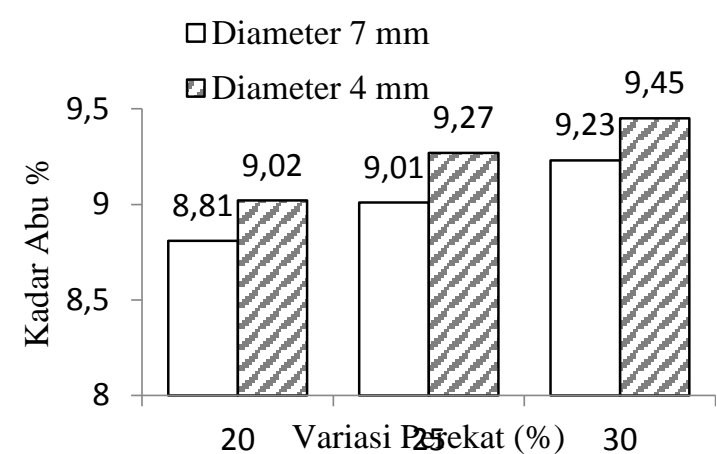

Gambar 10. Grafik perbandingan nilai kadar abu briket biopellet.

Menunjukan bahwa semakin banyak komposisi perekat yang digunakan maka kadar abu yang dihasilkan akan semakin besar dan didapatkan nilai dengan kadar abu terbanyak yaitu $9,45 \%$ variasi perekat $30 \%$ pada diameter briket biopellet $4 \mathrm{~mm}$ sedngkan kadar abu yang paling sedikit yaitu $8,81 \%$ pada variasi perekat $20 \%$ pada diameter $7 \mathrm{~mm}$. Hal ini disebabkan karena bahan dasar lem fox adalah air jadi jika perekatnya semakin banyak maka kadar abu akan bertambah.

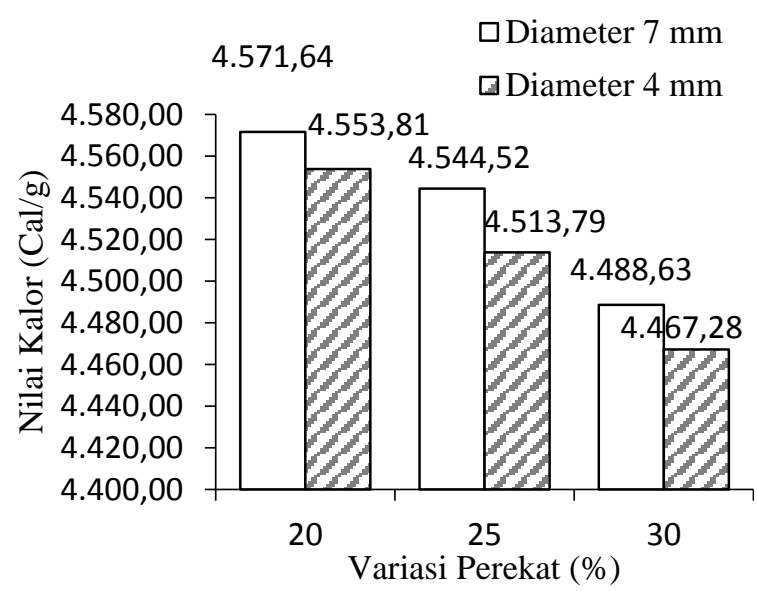

Gambar 11. Grafik perbandingan nilai kalor briket biopellet.
Dari hasil pengujian laboratorium mendapat nilai kalor tertinggi sebesar $4571.64 \mathrm{cal} / \mathrm{g}$ pada variasi perekat $20 \%$ pada diameter $7 \mathrm{~mm}$ sedangkan nilai kalor terendah sebesar $4467.28 \mathrm{cal} / \mathrm{g}$ pada variasi perekat $30 \%$ pada diameter briket biopellet $4 \mathrm{~mm}$. Hal ini di sebabkan karena campuran persentase perekat semakin sedikit, maka nilai kalor yang terdapat pada briket biopellet akan semakin besar, begitupun sebaliknya pemberian persentase perekat semakin banyak maka nilai kalor dari briket biopellet semakin rendah. Kalor yang semakin tinggi menunjukan kualitas bahan bakar yang semakin baik, kalor dipengaruhioleh kadar airdan kerapatan, nilai kalor berbanding terbalik dengan kadar air. Semakin tinggi kadar air pada suatu bahan bakar maka kalor yang dihasilkan akan semakin rendah [11].

\section{Kesimpulan}

Temperatur tertinggi sebesar $713,2^{\circ} \mathrm{C}$ didapatkan dari variasi perekat 20 $\%$ pada diameter briket biopellet $7 \mathrm{~mm}$ dan lama waktu nyala 26 menit. Dan temperatur terendah didapatkan sebesar $653,0^{\circ} \mathrm{C}$ pada variasi perekat $30 \%$ pada diameter briket biopellet $4 \mathrm{~mm}$ dan lama waktu nyala api 41 menit. Hasil pengujian laboratorium menunjukan bahwa nilai kadar air briket biopellet terbesar $8,10 \%$ pada variasi perekat $30 \%$ pada briket biopellet diameter $4 \mathrm{~mm}$ dan untuk nilai kadar abu briket biopellet terbanyak $9,45 \%$ pada variasi perekat $30 \%$ pada diameter briket biopellet $4 \mathrm{~mm}$, sedangkan untuk nilai kalor beriket biopellet tertinggi mencapai 4571,64 Cal/g pada variasi perekat $20 \%$ pada diameter briket biopellet $7 \mathrm{~mm}$.

\section{Referensi}

[1] Ariefin, A. (2019, Januari). Efektifitas Modifikasi Lubang Cetakan Terhadap Karakteristik Wood Pellet. In Prosiding Seminar Nasional Politeknik Negeri Lhokseumawe (Vol. 2, No. 1). 
[2] Ningrum,K dan Munawar. (2014). Pembuatan Biopelet dari Bungkil Jarak Pagar (Jathropacurcas L.) Dengan Penambahan Sludge dan Perekat Tapioka, (Skripsi). Fakultas Pertanian Teknologi Pertanian IPB. Bogor.

[3] Elfiano, E., Subekti, P., \& Sadil, A. (2014). Analisa Proksimat Dan Nilai Kalor Pada Briket Bioarang Limbah Ampas Tebu Dan Arang Kayu. Jurnal Aptek, 6(1), 57-64.

[4] Syamsiro, M. (2016). Peningkatan kualitas bahan bakar padat biomassa dengan proses densifikasi dan torrefaksi. Jurnal Mekanika dan Sistem Termal,

[5] Permata Sari D, (2019). Pembuatan Bahan Bakar Biopelet Dari Limbah Serbuk Gergajian.

[6] Windarwati. (2011). Uji Kinerja Rotary Dryer berdasarkan Efisiensi Termal Pengeringan Serbuk Kayu untuk Pembuatan Biopelet. Jurnal Teknik Kimia No. 2, Vol. 21, April 2011.

[7] Octaria, D. M. D. (2015). Prototipe Alat Pengering Biomassa Tipe Rotari (Uji Kinerja Rotary Dryer Berdasarkan Efisiensi Termal Pengeringan Serbuk Kayu untuk Pembuatan Biopelet) (Doctoral dissertation, Politeknik Negeri Sriwijaya).

[8] Junaidi, J., Ariefin, A., \& Mawardi, I. (2017). Pengaruh Persentase Perekat Terhadap Karakteristik Pellet Kayu Dari Kayu Sisa Gergajian. Jurnal Mesin Sains Terapan,

[9] Masitoh., Kurniati M., irzaman (2014). Analisa Diameter biopellet Sekam Padi Terhadap Efisiensi Energi Bahan akar. Jurnal SEMIRATA.

[10] Mumtahanah, H., \& Asngad, A. (2019). Uji Karakteristik Biobriket dari Kombinasi Bahan Tanaman Eceng Gondok (Eichornia crassipes) dan Tempurung Kelapa dengan Jenis
Perekat yang Berbeda (Doctoral dissertation, Universitas Muhammadiyah Surakarta). 